\title{
Enhancing Teaching Skills Through Short Courses: A Quantitative Review of Public Health Education in Sudan
}

\author{
Maye Omar', Amani Mustafa, ", Nada Mohamed Ali Alnair ${ }^{3}$, Amel Abdu Abdalla Gesmalla \\ Nour Ahmed Yousif Ahmed ${ }^{5}$, Nadia Yousif Mohamed Elemam ${ }^{5}$, Nabil Aziz ${ }^{6}$, Seseni Nu ${ }^{7}$, \\ Stephen Blount ${ }^{7}$, Sarah Yoss ${ }^{7}$, Dafallah Alam-Elhuda ${ }^{5}$
}

${ }^{1}$ Nuffield Centre for International Health and Development, Leeds Institute of Health Sciences, University of Leeds, Leeds, United Kingdom

${ }^{2}$ Public Health Training Initiative, The Carter Center, Khartoum, Sudan

${ }^{3}$ Global Health Directorate, Federal Ministry of Health, Khartoum, Sudan

${ }^{4}$ Human Resources Development Directorate, Federal Ministry of Health, Khartoum, Sudan

${ }^{5}$ Academy of Health Sciences, Federal Ministry of Health, Khartoum, Sudan

${ }^{6}$ Country Representative, The Carter Center, Khartoum, Sudan

${ }^{7}$ Special Health Projects, The Carter Center, Atlanta, GA, USA

\section{Email address:}

m.a.omar@leeds.ac.uk (M. Omar). amani.mustafa@cartercenter.org (A. Mustafa), nadaalnayer@gmail.com (N. M. A. Alnair), amolabdou@yahoo.com (A. A. A. Gesmalla), nouryousif0@gmail.com (N. A. Y. Ahmed), yousifnadia9@gmail.com (N. Y. M. Elemam), nabil.awadalla@cartercenter.org (N. Aziz), seseni.nu@gmail.com (S. Nu), Stephen.blount@cartercenter.org (S. Blount),

Sarah.Yoss@cartercenter.org (S. Yoss), dafoua@yahoo.com (D. Alam-Elhuda)

${ }^{*}$ Corresponding author

\section{To cite this article:}

Maye Omar, Amani Mustafa, Nada Mohamed Ali Alnair, Amel Abdu Abdalla Gesmalla, Nour Ahmed Yousif Ahmed, Nadia Yousif Mohamed Elemam, Nabil Aziz, Seseni Nu, Stephen Blount, Sarah Yoss, Dafallah Alam-Elhuda. Enhancing Teaching Skills Through Short Courses: A Quantitative Review of Public Health Education in Sudan. Science Journal of Public Health. Vol. 8, No. 4, 2020 , pp. 115-122. doi: $10.11648 /$ j.sjph.20200804.14

Received: April 14, 2020; Accepted: April 30, 2020; Published: July 4, 2020

\begin{abstract}
This evaluation draws evidence on the effectiveness and outcome of learning and teaching courses that were offered to a number of teaching staff of the Academies of Health Sciences, Midwifery Schools and Centres for Continuous Professional Development in Sudan. It is based on a cross-sectional study consisting of self-administered questionnaires conducted from October 2017 to January 2018. The questionnaires were used to measure the extent to which the participants of the training courses acquired knowledge and skills and applied these skills in their jobs. Data was analysed using Excel sheets and SPSS version 21 and significant tests performed. The response rate for the self-administered questionnaire was $80 \%$. Most of participants were females, early middle-aged, bachelor's degree holders with more than 9 years of experience in the area of teaching health care professionals. The results are presented following the Kirkpatrick framework for evaluation of training, which was used to measure participants' reactions, learning and change of behaviour. Most of the participants were satisfied with the design and content of the course but expressed concerns regarding its duration and lack of residential facilities for course participants. Pre and post tests were used to measure learning. Comparison of the two results showed that participants gained knowledge in writing learning outcomes, although presentation skills showed no improvement following the training and the use of technology remained a challenge even after the course. In terms of application of the newly gained knowledge and skills, the findings illustrated that over $90 \%$ of the participants were satisfied with what they had learned after 3 months or more following the training course, and over $65 \%$ of the participants stated that the knowledge gained from the training remained useful. In conclusion, short courses on teaching and learning can be a valuable investment to both instructors and students. The evaluation has shown that course participants were satisfied with the training courses, gained new knowledge, and were able to apply the acquired knowledge and skills without any difficulties. It is therefore suggested to cascade these training courses to all remaining States in Sudan in order to improve the skills and capabilities of teaching staff.
\end{abstract}


Keywords: Capacity Development, Human Resources Development, Kirkpatrick Model, Training Evaluation, Training Institutions, Training of Trainers, Public Health, Sudan

\section{Background}

The Sudan Public Health Training Initiative (SPHTI) is a project led by the Government of Sudan and The Carter Center (TCC) aimed at strengthening the capacity of Sudanese training institutions to train frontline health workers with an appropriate skill mix to meet the maternal and child health needs of rural and urban communities. SPHTI supports Sudanese training institutions to develop a health workforce capable of delivering health interventions to support the achievement of the Sustainable Development Goals (SDG) and the promotion of population health [1-3].

SPHTI launched a capacity building programme for public health training institutions, namely; the Academies of Health Sciences (AHS) and the Continuing Professional Development Centre (CPD). AHS is a training institution established by the Ministry of Health to train nurses, midwives, and other allied health professionals throughout the country, while the CPD focuses on providing professional development for practicing health care workers to refresh and improve their skills. SPHTI aims to build the capacity of health science teachers by availing appropriate training and health learning materials based on the local context, and supporting local health professional training institutions to adopt innovative learning approaches [4]. Accordingly, fourteen short courses on "learning and teaching" were designed and delivered to 310 participants for all the eight SPHTI target States, namely Northern State, River Nile, Gazeira, Sennar, White Nile, North Kordofan, West Kordofan, and South Kordofan (Figure 1). An evaluation of those training inputs to determine the impact of the training will help to assess the effects on the performance of trainees and the overall improvement of institutional performance.

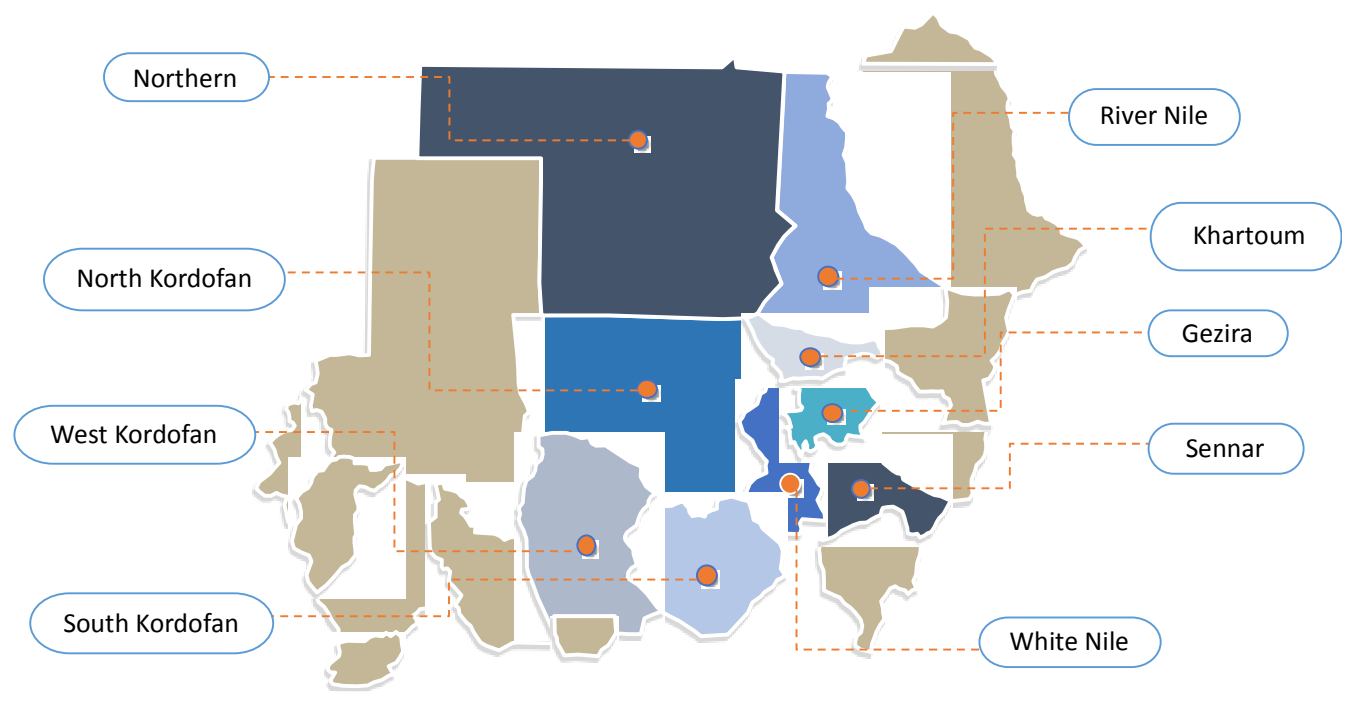

Figure 1. Map of Sudan showing SPHTI target states.

\subsection{Training Evaluation}

According to Frye and Hammer there are four common models for educational/training evaluation [5]. These include the experimental/quasi experimental; logic; the context/input/process/product (CIPP); and Kirkpatrick fourlevel models [5].

In this study, the Kirkpatrick's four-level model was applied to enable SPHTI to examine various levels of results and stimulate Sudanese training leaders to increase their efforts in evaluating training programs. This model has been used to evaluate similar training programmes elsewhere [68]. The four levels of the framework are illustrated in table 1 [6].

Table 1. Kirkpatrick 4 levels framework and measurements.

\begin{tabular}{ll}
\hline Levels & Measurements \\
\hline Level one: Participant's Reaction & $\begin{array}{l}\text { Trainee's reaction and feelings about the various aspects of the training programme and satisfaction with the } \\
\text { programme. It does not measure any learning but is used to assess the content and design in order to evaluate the } \\
\text { relevance and usefulness of the training. It is usually administered immediately after the training using an } \\
\text { evaluation form. }\end{array}$ \\
$\begin{array}{l}\text { Trainee's knowledge and demonstration of skills to assess the achievement of the identified learning objectives in } \\
\text { terms of quantitative results. The evaluation is conducted immediately after the training. A "before" and "after" } \\
\text { Learning }\end{array}$ & \begin{tabular}{l} 
approach should be used where possible "in form of pre and post-test". \\
\hline
\end{tabular}
\end{tabular}




\begin{tabular}{ll}
\hline Levels & Measurements \\
\hline $\begin{array}{l}\text { Level three Behaviour change or } \\
\text { impact }\end{array}$ & $\begin{array}{l}\text { Changes in behavior and/or attitude and the application of the newly acquired knowledge and skills to evaluate the } \\
\text { actual on the job performance a few months after completion of training. This level of evaluation requires that } \\
\text { information is obtained from people who have attended the training, their work supervisors as well as colleagues in } \\
\text { the setting who are able to comment on changes that have taken place that could be attributed to the training } \\
\text { programme. }\end{array}$ \\
$\begin{array}{l}\text { Level four Organizational change or } \\
\text { utilization of services. However, it is often difficult to separate it from other variables in order to determine the } \\
\text { proportion of improvement that could be attributed solely to the training. }\end{array}$ \\
\hline
\end{tabular}

\subsection{Aims of the Evaluation}

This evaluation is meant to draw evidence regarding the outcome of the training courses in learning and teaching that were conducted in Sudan. Therefore, the aim of the evaluation was to assess the effectiveness of the teaching and learning courses in terms of participants' level of satisfaction, knowledge and skills gained and improved performance [9]. It was outside the scope of this evaluation to assess the fourth level of the Kirkpatrick model, organizational change or results, given the time period of the evaluation and the difficulty of assessing attribution at that level. Further research would be needed to assess the impact of the training program on any organizational change at the training institutions.

\section{Methodology}

The study was a cross-sectional [10], institution-based quantitative investigation conducted in the Academy of Health Sciences (AHS), Midwifery Schools (MS) and Continuous Professional Development (CPD) Centers in the eight States of Sudan that are supported by The Carter Center Sudan (TCC) Public Health Training Initiative (SPHTI). This study took place from October 2017 to January 2018. The study subjects included teaching staff who participated in previous PHTI learning and teaching short courses, using self-administered questionnaires.

Study variables included participants' demographic data and reflections on the training programme as well as knowledge and skills gained in the various training components such as, learning outcomes, presentation skills, teaching methods, lesson planning, curriculum design, student supervision, student assessment and training evaluation.

A variety of statistical measures were undertaken to identify patterns or trends (descriptive statistics) and assess inferences about the general study population that can be made from the data (inferential statistics). The data was analyzed using SPSS (statistical package for social science programme) version 21 for Windows and the result are expressed in figures, charts and tables. Data was analysed by using the chi-square and paired sample t-tests with a $P$ value of $5 \%(0.05)$ and $95 \%$ confidence interval.

The results are presented following the Kirkpatrick framework for evaluation of training which was used to measure participants' reactions, learning, and application of gained knowledge in their job.

\section{Findings}

A total of 287 out of the 360 teaching staff from SPHTI supported institutions completed the self-administered questionnaire, giving an overall $80 \%$ response rate. The respondents were all health professionals working in the AHS, MS and CPD in 8 States of Sudan and the central level as shown in table 2.

Table 2. Distribution of participants per state, $n=287$.

\begin{tabular}{lll}
\hline State & Frequency & Percent \\
\hline Gezira & 70 & 24.4 \\
Sinnar & 36 & 12.5 \\
White Nile & 28 & 9.8 \\
Northern State & 23 & 8.0 \\
River Nile & 32 & 11.1 \\
North Kordufan & 27 & 9.4 \\
South Kordufan & 11 & 3.8 \\
West Kordufan & 29 & 10.1 \\
khartoum & 31 & 10.8 \\
Total & 287 & 100.0 \\
\hline
\end{tabular}

More than half of the participants $(53 \%)$ were from the AHS. Females were predominant (64\%) and $66 \%$ of the respondents were 30-49 years old, which is the most productive age justifying an investment of in-service training and skills enhancement to improve their performance in training and education (WHO, 2006).

The educational qualification of the participants showed that, $2 \%$ of the respondents hold $\mathrm{PhD}, 38 \%$ Master's degrees, $40 \%$ Bachelor's degrees and $20 \%$ health profession diplomas. The experience of the health professional educators is important for effective implementation of the curriculum. In this regard, $40 \%$ of the respondents had more than 9 years of teaching experience, whereas another $32 \%$ had $5-9$ years of experience and the remaining $28 \%$ had $2-4$ years of experience in a teaching career.

The appropriate selection of participants for this course was key to learning and eventual success of the training. In this regard, $94 \%$ of people who attended the short courses were nominated by their managers and supervisors in response to the needs of the institutions. Whereas the remaining $6 \%$ made individual applications to participate in the learning and teaching courses in recognition of the need to develop teaching and learning skills.

a) Level One: Participants' Reactions

This level of the Kirkpatrick model measures participants' reaction to, and satisfaction with, the overall training programme. Participants' reaction to the training programme 
was evaluated at the end of each training course. Respondents were asked to evaluate achievement of the training objectives, programme organization, place of training, services provided by facilitators, benefits of the training, relevance of training materials, quality of training materials, and effectiveness of training methods.

Participants' satisfaction with the training programme was rated on a five-point Likert scale which ranged from strongly agree to strongly disagree. As shown in figure 2, the majority of participants were satisfied with the design and content of the course. Most of them were satisfied in achieving training objectives, however, some participants rated the training slightly lower on items related to logistics and quality of training materials on time.

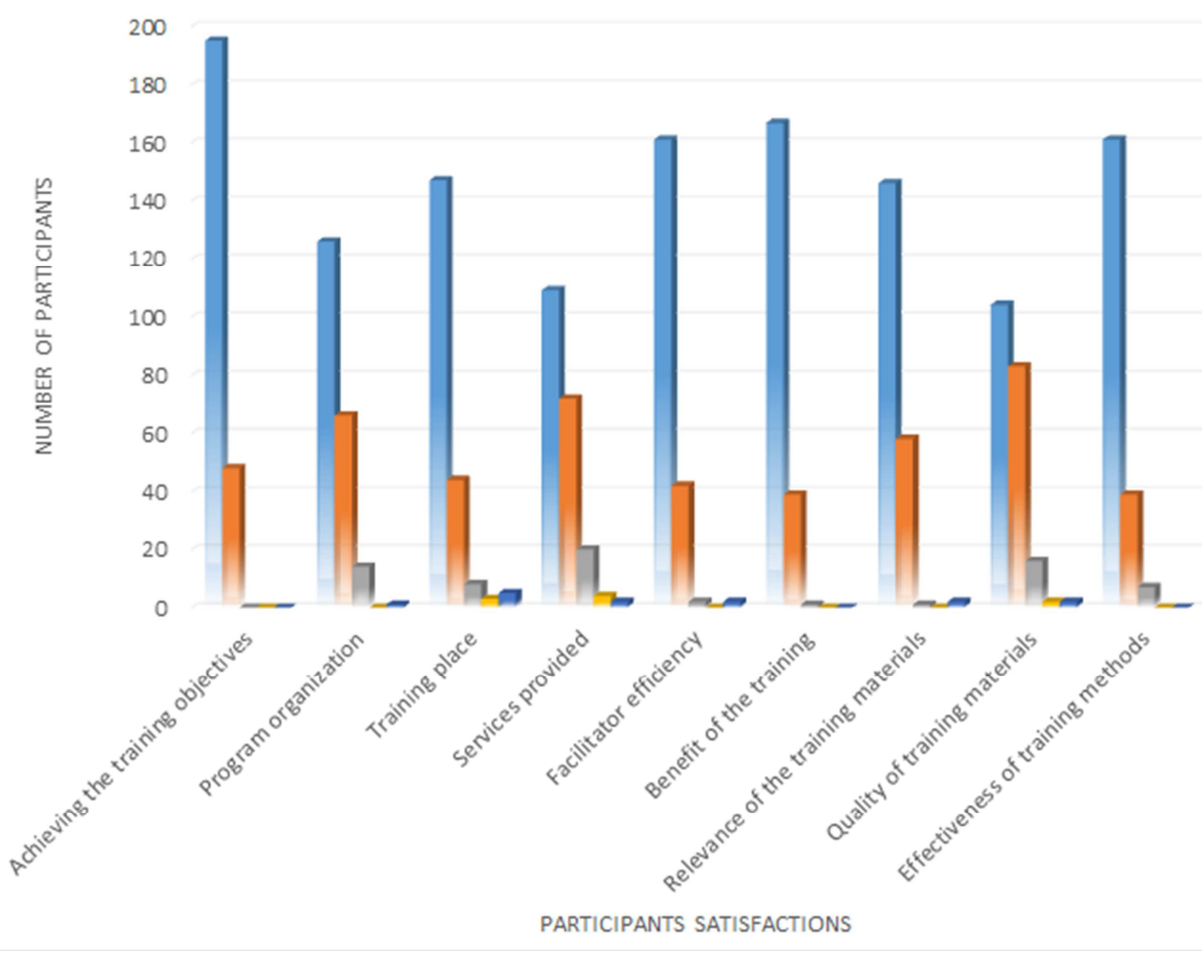

Figure 2. Participants' satisfaction with the overall training programs, $N=207$.

Regarding the length of the training programme, $61.8 \%$ of the respondents stated that the duration of training was adequate. Moreover, 97\% stated that they would recommend this course for their colleagues.

Almost $99.5 \%$ of respondents felt that the training objectives were attained and 98\% acknowledged that the training programme was relevant and related strongly with the work they are doing as instructors.

In order to assess satisfaction levels, a qualitative, open end question was administered to elicit qualitative responses. The questions included, what they considered were the best things about the course, challenges they faced during the course, and suggestions to improve the course. Data was analyzed and ranked in descending order based on participants' response into the following tables. Table 3 provides a summary of participants' perception about the best things, whereas table 4 presents challenges that participants faced during the course, and table 5 lists participants views of what needs to be improved.

Table 3. Participants perception on what were the best things about the course.

1. Location of the course

2. Gang theory.

3. Coordination of the training programme.
4. Clarity and relevance of training objectives.

5. Certificate from The Carter Centre.

6. Excellent logistics and other services.

7. Competencies and skills of trainers and training approaches.

Table 4. Participants perception of challenges they faced during the course.

1. Time was short.

2. There was no provision of lodging for participants who are not resident in the area.

3. Transportation issues because of distance.

4. At times issues of punctuality of course participants that affected proper use of available time.

Table 5. Participants' suggestion for course improvement.

1. Extend the duration of the course and reduce the number of hours per day.

2. Simplify and explain new and unfamiliar terms.

3. Provide handouts in both soft and hard copies at the start of the course.

4. Provide place to stay and transport facilities for non-residents.

5. Make computers available for course participants.

6. Add a session on monitoring and evaluation of programmes.

Considering the methodology of delivering this session, the skills and competency of the facilitator, suitability of the subjects and usefulness of training, these were rated high by the participants during the course as illustrated in Figure 3. 


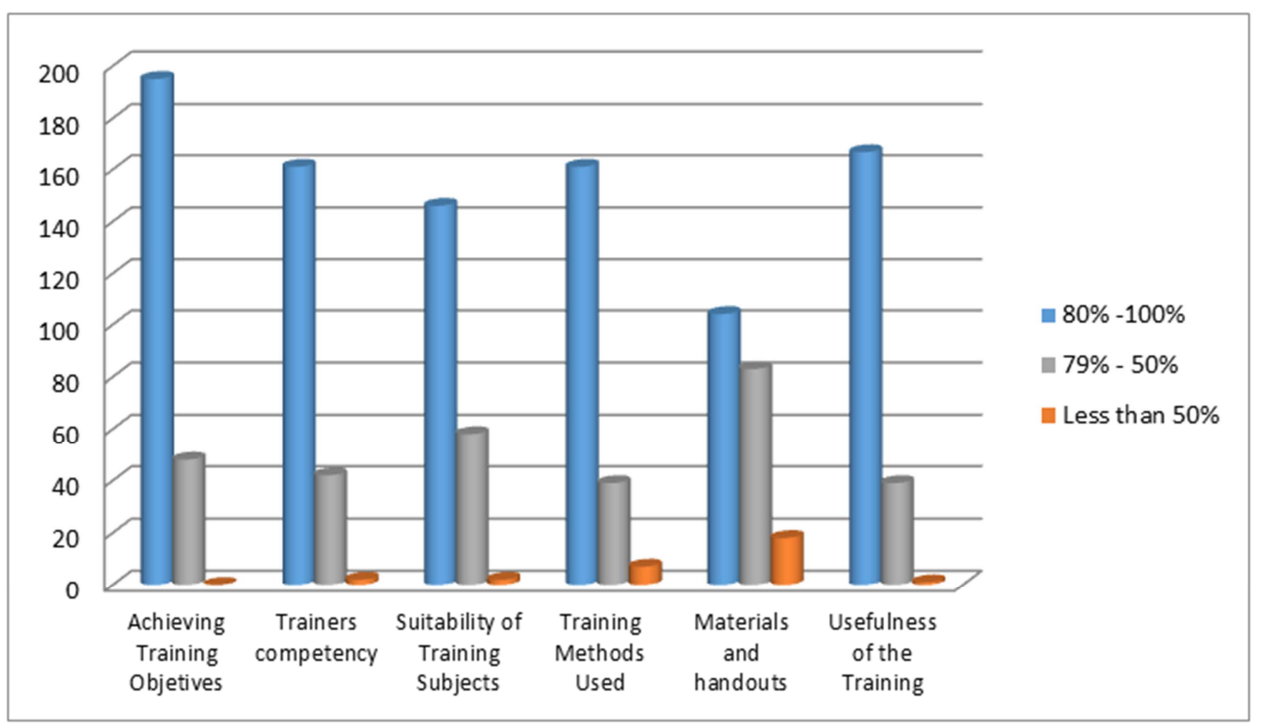

Figure 3. Participants level of satisfaction on different aspects of the course.

b) Level Two: Learning

This level of the Kirkpatrick model measures the knowledge and skills gained during the training courses. In this evaluation, changes in knowledge of participants was assessed using the same pre- and post-test before and after each course to gauge their level of learning. The results of these tests were analyzed and compared to find out the knowledge gained by the participants after the training and to guide future training design. The pre- and post-test were designed to cover all the topics of the teaching sessions covered by the training course.

Overall 212 respondents completed pre-test and 207 posttest questions. The results were analysed against the nine areas covered during the training courses to compare changes relating to knowledge aspects (Figure 4).

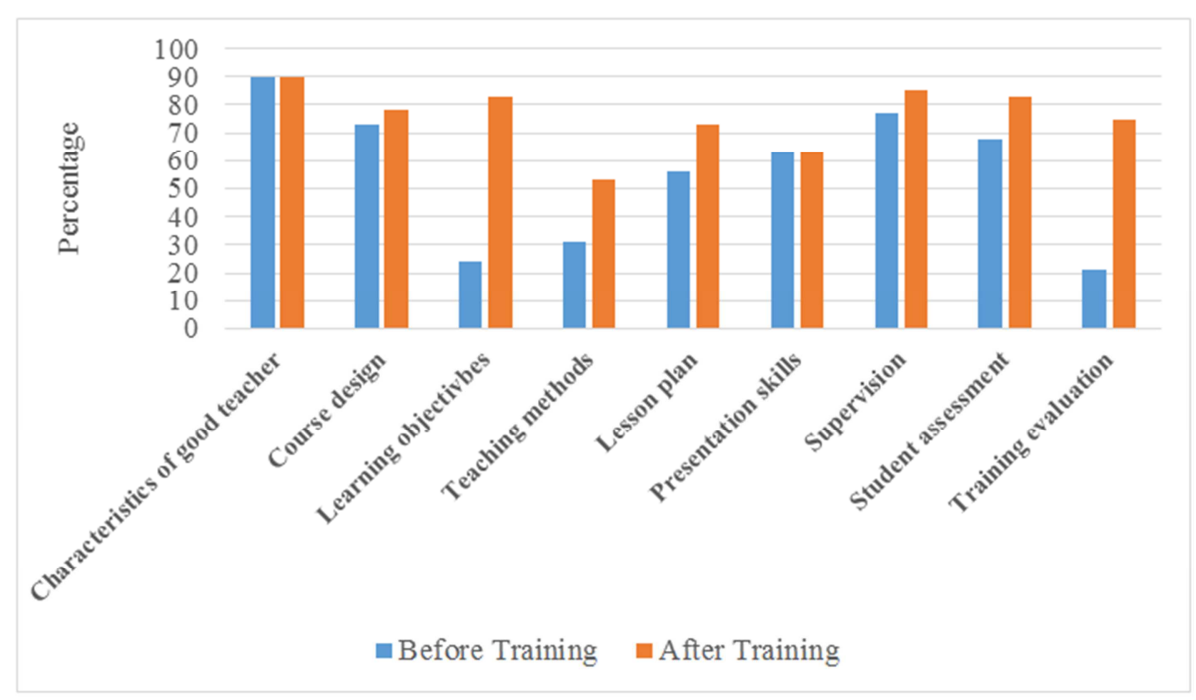

Figure 4. Pre and post-test training knowledge improvement - $N=212$ for pre-test and 207 for post-test.

The knowledge gained by the training course participants increased markedly. In particular, 59\%, 22\% and 54\% demonstrated increased knowledge in regard to the subjects of learning objectives, teaching methods, and training evaluation respectively. The knowledge gained in those three areas was statistically significant as shown in Table 6 .

Table 6. Significance of pre and post-test training knowledge improvement.

\begin{tabular}{lllll}
\hline \multirow{2}{*}{ Learning domains } & Pre test & \multicolumn{2}{l}{ Post test } \\
\cline { 2 - 4 } & Percentage & Mean & Percentage & Mean \\
\hline Learning objectives & 24 & 16.67 & 83 & 59.00 \\
Characteristic of good instructors & 90 & 62.00 & 90 & 63.33 \\
Presentation skills & 63 & 43.67 & 63 & 44.67 \\
Teaching methods & 31 & 21.67 & 53 & 0.00 \\
\hline
\end{tabular}




\begin{tabular}{|c|c|c|c|c|c|}
\hline \multirow{2}{*}{ Learning domains } & \multicolumn{2}{|l|}{ Pre test } & \multicolumn{2}{|l|}{ Post test } & \multirow{2}{*}{ p value } \\
\hline & Percentage & Mean & Percentage & Mean & \\
\hline Lesson plan & 56 & 38.33 & 73 & 51.67 & 0.00 \\
\hline Training evaluation & 21 & 14.67 & 75 & 52.70 & 0.00 \\
\hline Student assessment and feedback & 68 & 47.00 & 83 & 58.33 & 0.40 \\
\hline Curriculum design & 73 & 50.67 & 78 & 55.00 & 0.00 \\
\hline Student supervision & 77 & 53.33 & 85 & 60.00 & 0.00 \\
\hline
\end{tabular}

The knowledge about the topic of characteristics of a good instructor was very high $(90 \%)$ among the participants and remained the same before and after the training, which indicates that participants had sufficient prior knowledge in this area. Similarly, the knowledge regarding presentation skills remained constant at $63 \%$ both before and following the training

Additionally, Table 6 showed that the knowledge gained in the presentation skills domain was statistically insignificant.

On the subject of teaching methods, the knowledge gained has increased from $31 \%$ to $53 \%$ among the participants, which is significant $(\mathrm{P}$ value $=0.000)$. Such a gain was also observed for lesson plan subject, with knowledge increasing from $56 \%$ to $73 \%$ among the participants ( $\mathrm{P}$ value $=0.000$ ). Knowledge regarding student assessment and feed-back has improved from $68 \%$ to $83 \%$, but this was statistically insignificant result, because the p value of T test was 0.40 .

The course design and supervision topics knowledge was improved among $73 \%$ to $78 \%$ and $77 \%$ to $85 \%$ of the participants respectively. In the next level of this evaluation we will compare the knowledge findings with the application.

c) Leve Three: Behavior Change

This level of Kirkpatrick model measures the behavior, i.e. attitude and practices in regard to the application of the newly acquired knowledge and skills in the work setting. The evaluation was carried out after more than 3 months following training. Participants who attended the training were asked about their views on the training courses provided by PHTI and their usefulness to the context of Sudan.

i. Participants' views on the course

The evaluation explored the extent to which participants were still satisfied of what they had learned from the course after 3 months or more following the training programme.

The evaluation also investigated the extent to which the trained instructors were still satisfied 3 months or more after and they applied the training knowledge and skills in their work. The findings as illustrated in Table 7 show that the majority of respondents were still satisfied with the all aspects of training and agreed that the course was worth the time it took.

Table 7. Instructors views in percentages on courses after more than three of attending the course and application of course knowledge and skills in practice.

\begin{tabular}{|c|c|c|c|c|c|}
\hline Item & SA* & $\mathbf{A}^{*}$ & $\mathbf{N}^{*}$ & D* & SD* \\
\hline The course was interesting & 83.3 & 16 & 0 & 0 & 0.7 \\
\hline The course changed the instructor's ways of doing things & 66.9 & 31.7 & 0.7 & 0 & 0.7 \\
\hline The course changed the instructor's way of thinking & 61.7 & 32.8 & 2.4 & 1.4 & 1.7 \\
\hline The course was worth the time it took & 41.8 & 35.2 & 5.6 & 12.9 & 4.5 \\
\hline The course helped the trained instructor's career & 70 & 27.2 & 1 & 0.3 & 1.4 \\
\hline The course made the trained instructors realized the importance of continuous learning & 72.5 & 24.7 & 1.4 & 0.3 & 1 \\
\hline The instructors' boss valued this course & 57.8 & 32.1 & 5.2 & 1.4 & 3.1 \\
\hline $\begin{array}{l}\text { A strength of this course is that it gave the trained instructors the chance to meet other } \\
\text { colleagues from different institutions }\end{array}$ & 76.7 & 19.5 & 2.1 & 0.7 & 1 \\
\hline There was too much emphasis on theory & 38.7 & 38.7 & 6.3 & 14.3 & 2.1 \\
\hline There was too much emphasis on practical & 38 & 37.3 & 10.5 & 10.5 & 3.8 \\
\hline There was an acceptable blend of theory and practice in the course & 48.1 & 35.9 & 8.7 & 5.6 & 1.7 \\
\hline There should be more courses of this nature & 82.9 & 15.3 & 0 & 0.3 & 1.4 \\
\hline Sharing learning with other colleagues & 65.5 & 31 & 1 & 1 & 1.4 \\
\hline
\end{tabular}

*SA=strongly agree, $\mathrm{A}=$ agree, $\mathrm{N}=$ neutral, $\mathrm{D}=$ disagree, $\mathrm{SD}=$ strongly disagree

\section{ii. Usefulness of the Courses}

This part focused on the usefulness of the training courses; the answers were respondents' self-assessment of the following:

1) The usefulness of the gained knowledge (learning domains)

2) The ability to apply the acquired knowledge

3) The application of gained knowledge without any difficulties

4) Usefulness of the Knowledge Gained

Respondents were asked to rate the useful of the courses in regard to different learning domains. In this regard, more than $65 \%$ of the respondents stated that the gained knowledge was useful. In particular they stated that lesson plan and presentation skills were the most useful learning domains and was mentioned by $81.9 \%$ and $76.5 \%$ of the participants respectively, whereas, student assessment and learning outcomes were mentioned as useful by $68.5 \%$ and $69.2 \%$ of the participants respectively.

1) The Ability to apply the acquired knowledge

More than $60 \%$ of the respondents stated that they were able to apply and use the gained knowledge in their teaching sessions. Lesson planning and student supervision were the most applied learning domains, being used by $79.8 \%$ and 
$70.8 \%$ of the respondents respectively. Teaching methods and student assessment, on the other hand were applied by $63.8 \%$ and $65.1 \%$ of the respondents respectively.

2) Application of gained knowledge without any difficulties

Respondents were asked to what extent they feel that they are able to make use of the knowledge and skills gained from the course without difficulties from the working environment. In this regard, $75 \%$ of respondents stated that they were able to apply gained knowledge without any difficulties as illustrated in Figure 5. Student supervision and lesson planning appeared to be most applied learning domains without any difficulties, being reported by $77.6 \%$ and $73.5 \%$ of the respondents respectively. Whereas, learning objectives and presentation skills were applied by $69.5 \%$ and $70.2 \%$ of the respondents respectively.

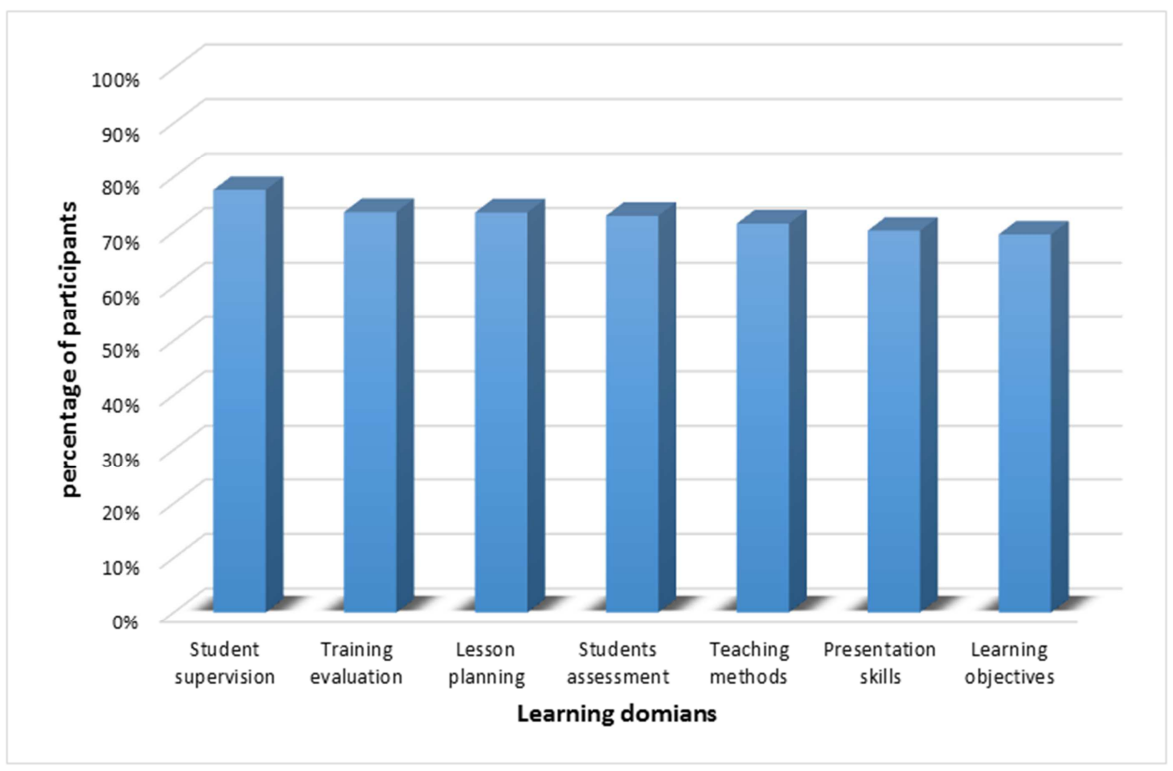

Figure 5. Application of gained knowledge without difficulties $(n=287)$.

As illustrated in Table 8, the findings suggest that statistically there is a strong association between the usefulness, application of gained knowledge and application without difficulties. The $\mathrm{p}$-value of chi-square was significant in all areas of learning ( $\mathrm{p}$ value $=0.000)$.

Table 8. The association between the usefulness and application of gained knowledge by participants.

\begin{tabular}{|c|c|c|c|c|c|}
\hline Areas of learning & Usefulness $\%$ & Application\% & Application without difficulties \% & Chi-square value & $P$ value \\
\hline Learning objectives & 69.2 & 66.9 & 69.5 & 145.978 & 0.000 \\
\hline Presentation skills & 76.5 & 68.5 & 70.2 & 153.76 & 0.000 \\
\hline Teaching methods & 70.2 & 63.8 & 71.5 & 157.98 & 0.000 \\
\hline Student assessment & 68.5 & 65.1 & 72.9 & 172.23 & 0.000 \\
\hline Training evaluation & 76.2 & 71.1 & 73.6 & 130.14 & 0.000 \\
\hline Lesson plan & 81.9 & 79.8 & 73.5 & 105.1 & 0.000 \\
\hline Student supervision & 70.4 & 70.8 & 77.6 & 162 & 0.000 \\
\hline
\end{tabular}

\section{Discussion}

Evaluating training courses on teaching and learning is a key to ensuring that training courses have improved the instructors' capabilities and skills and consequently enhanced student learning [11]. The evaluation focused on the participants' reactions, gained knowledge and application of acquired skills in order to assess the extent to which learning outcomes of the training course are achieved [12].

An analysis of findings revealed that the participants were satisfied with the design and content of the training courses. Moreover, they acquired new knowledge in all areas that were covered by the courses with the exception of sessions such as 'the characteristics of good instructors', which they were already familiar with. Limitations of computer and technology use acted as a barrier for some participants to apply what they have learned to enhance and improve their presentation skills. Lack of improvement in presentation skills may also be due to the way the test questions were constructed, or may be an indication that more practical sessions are needed to enhance the theoretical part that is covered in the training course [13].

One of the major achievements of these courses was that the participants were made aware of the usefulness of these short courses in all learning domains [14]. Most of the participants were able to apply the knowledge and skills acquired in their teaching without any difficulties. However, the main difficulties were in writing specific, meaningful, appropriate, realistic and testable (SMART) learning outcomes and improving presentation skills through the use of technology. 
For both AHS and CPD instructors, the ability to write (SMART) learning outcomes was a new experience; they required more training and practice in order to be able to apply without any difficulties. Refresher courses and a training manual will likely help instructors to write these SMART learning outcomes accurately. Presentation skills needed technology and PowerPoint use and the findings have shown that some instructors had limited experiences with technology and therefore need to develop their capabilities in this area. Follow-up training courses are therefore needed to fill those gaps in regard to the use of PowerPoint Presentation and SMART learning outcomes.

This evaluation could have looked into the learning results to identify such weakness before launching the field study for data collection. Therefore, the findings may need more indepth discussion with the participants to identify the reasons of lack of improvement in the knowledge of presentation skills in order to affect changes in future trainings.

\section{Conclusions}

In conclusion, short courses on Teaching and Learning were found to be a valuable investment to both participants of the courses and their students in all training institutions [15]. This calls for the need to expand, extend and cascade these training courses to all remaining States in Sudan in order to improve the skills and capabilities of teaching staff. This will contribute towards the development and training of competent health professions who will have the appropriate knowledge, relevant skills and attitude to serve the people and enhance the performance of the health system in Sudan.

\section{References}

[1] UN. Transforming our world: the 2030 agenda for sustainable development. New York; 2015.

[2] Jha A, Kickbusch I, Taylor P, Abbasi K. Accelerating achievement of the sustainable development goals. BMJ. 2016; 352: i409.

[3] WHO. Working together for health. Geneva: WHO; 2006.

[4] Downes E, Wold J, Belatchew M, Mustafa A, Blount S.
Strengthening Educational Capacity through Context-Relevant Curriculum Design and Evaluation. Frontiers in Education. 2017; 2 (29).

[5] Frye AW, Hemmer PA. Program evaluation models and related theories: AMEE Guide No. 67. Medical Teacher. 2012; 34 (5): e288-e99.

[6] Omar M, Gerein N, Tarin E, Butcher C, Pearson S, Heidari G. Training evaluation: a case study of training Iranian health managers. Human Resources for Health. 2009; 7 (1): 20.

[7] Ridde V, Fournier P, Banza B, Tourigny C, Ouédraogo D. Programme evaluation training for health professionals in francophone Africa: process, competence acquisition and use. Human Resources for Health. 2009; 7 (1): 3.

[8] Rotem A, Zinovieff MA, Goubarev A. A framework for evaluating the impact of the United Nations fellowship programmes. Human Resources for Health. 2010; 8 (1): 7.

[9] Mertens DMaW, A. T. Program Evaluation Theory and Practice - Second Edition A Comprehensive Guide: Guilford Press; 2018.

[10] Hall J. Cross-Sectional Survey Design. 2008 2020/03/25. In: Encyclopedia of Survey Research Methods [Internet]. Thousand Oaks Thousand Oaks, California: SAGE Publications, Inc.; [173]. Available from: http://sk.sagepub.com/reference/survey.

[11] Hiner CA, Mandel BG, Weaver MR, Bruce D, McLaughlin R, Anderson J. Effectiveness of a training-of-trainers model in a HIV counseling and testing program in the Caribbean Region. Human Resources for Health. 2009; 7 (1): 11.

[12] Miller BM, Eichbaum Q, Brady DW, Moore DEJ. Aligning Health Sciences Education with Health Needs in Developing Countries. Academic Medicine. 2011; 86 (11): e10.

[13] Saks AM, Burke LA. An investigation into the relationship between training evaluation and the transfer of training. International Journal of Training and Development. 2012; 16 (2): 118-27.

[14] Ravet J. From interprofessional education to interprofessional practice: exploring the implementation gap. Professional Development in Education. 2012; 38 (1): 49-64.

[15] Celletti F, Reynolds TA, Wright A, Stoertz A, Dayrit M. Educating a new generation of doctors to improve the health of populations in low- and middle-income countries. PLoS Med. 2011; 8 (10): e1001108. 